\title{
The Implementation and Reference of British Government Environmental Responsibility Audit
}

\author{
Yamei Guan*, Wenzhou Zhong \\ Nanjing University of Finance and Economics, Nanjing City, P.R.China, 210023 \\ ${ }^{*}$ Corresponding author. Email: guanyamei@sina.com
}

\begin{abstract}
The pilot work of the environmental responsibility audit of the government of China has been carried out. After analyzing it, it is found that the content of audit is not unified, the evaluation standard is not comprehensive and so on. The British government environmental responsibility audit is relatively mature and China can use it for reference appropriately.
\end{abstract}

Keywords: Government audit, Environmental responsibility, Natural resources audit.

\section{INTRODUCTION}

The British environmental responsibility audit system is quite mature and complete. It not only audits the financial statements of government agencies, but also conducts special audit investigations on environmental performance. Due to the rise of the Industrial Revolution in the UK, the British environmental problems have become more serious. In recent years, the authorities have continued to pay close attention to environmental behavior and have implemented a high degree of supervision over the government environmental responsibility audit.

\section{THE MAIN CONTENT OF THE BRITISH GOVERNMENT ENVIRONMENTAL RESPONSIBILITY AUDIT}

\subsection{The Environmental Responsibilities of the Government}

When implementing environmental responsibility audit, an investigation of the environmental area under the jurisdiction of the audited unit shall be conducted in the early stage. The National Audit Office conducted investigations into individual regions, and based on the integrated analysis of the environmental status of different regions, the overall trend was obtained. The Environmental Audit Committee of the House of Commons of the United Kingdom made a request to the National Audit Office to inspect and issue assessment reports on each of the ten prescribed environmental governance projects. According to the survey results of each project, the National Audit Office believes that environmental protection improvements and challenges coexist.

\subsection{The Government's Responsibility for Sustainable Development}

In terms of sustainable development, the British government achieves this goal through policy formulation, procurement and management of government assets and so on. The Treasury stipulates that governments at all levels must disclose sustainability matters and form special reports. The National Audit Office will formulate a corresponding audit plan, audit such reports and evaluate the implementation of the central government's sustainability strategy. Furthermore, the National Audit Office conducts inspections on the procurement and operations of government departments' asset, and management decisions, etc. In terms of sustainable development, the National Audit Office is not only limited to the sustainability of environmental resources, but also categorizes sectors such as health services and technological innovation into the sustainable scope. For example, the results of the audit work conducted by the Home Office showed that the Home Office did not adhere to the principle of sustainability in the management of shelter assets, but the department's environmental impact on government-sponsored construction projects and government business trips has gradually become green. In general, the sustainability 
work of the Home Office is more effective.

\section{RESULTS OF THE BRITISH GOVERNMENT ENVIRONMENTAL RESPONSIBILITY AUDIT}

\subsection{Release of Concise Guide to Environmental Protection and Sustainable Development}

The National Audit Office issued Concise Guide to Environmental Protection and Sustainable Development to provide policy guidance on resource allocation specifically for environmental protection topics and sustainable projects. For example, the budget and allocation of environmental special funds, the development and implementation of sustainable projects, and the planning of important government affairs are all policy guidances. This guide is consistent with the requirements of the United Nations' sustainable development goals and humans' conventional understanding of environmental protection. Based on the pain points in previous annual audit reports, and with reference to relevant reports provided by relevant departments, the guide reports on the implementation status, work results, existing problems, project planning and future vision of the UK government and relevant departments on environmental protection and sustainable development. The purpose is to conduct a comprehensive analysis of the overall performance of the British government environmental responsibility audit.

\subsection{Release of the Government Environmental Responsibility Audit Briefing}

The British House of Commons is in charge of the National Audit Office. The auditor -general of the National Audit Office is appointed by the House of Commons and is responsible for reporting to the House of Commons on the performance of government departments' resource and environmental responsibilities. In addition, the House of Commons has also set up the Environmental Audit Committee, the Environmental Food Committee and the Rural Affairs Committee. They also have the power to request the National Audit Office to provide government environmental responsibility audit briefings. The Departmental Observation is a comprehensive work report which mainly reflects the full range of work activities and departmental performance. It was compiled by using the announcements, publications issued by the audited units and the resources and data collected by the National Audit Office through investigations. It is a comprehensive environmental protection report that reflects the audited unit's environmental activities, environmental performance, and project risks from multiple aspects. In recent years, the National Audit Office has launched investigations into relevant departments on issues of particular concern to the ministry of energy and climate change, environmental food and rural affairs.

\subsection{Release of Departmental Environmental Responsibility Audit Report}

The departmental environmental responsibility audit report is a special audit report specifically aimed at the implementation of environmental responsibilities of environmental management departments and environmental governance agencies. Its professionalism and specificity are different from the above two audit reports. The report reflects the environmental governance of the audited entity and the problems in the governance process. The preparation content of the Concise Guide to Environmental Protection and Sustainable Development, Departmental Observation and Departmental Sustainability Observation can be extracted from the departmental environmental responsibility audit report.

\section{THE FEATURES OF THE BRITISH GOVERNMENT ENVIRONMENTAL RESPONSIBILITY AUDIT REPORT}

\subsection{The Conclusions of Government Environmental Responsibility Audit have been Verified by Multiple Parties}

The UK's published environmental responsibility audit report is an audit document which collected resources and information from multiple sources. In addition to collecting audit evidence and implementing analytical procedures, the National Audit Office also used documents and data from other departments and agencies to more specifically and comprehensively reflect the performance and implementation of government departments' environmental responsibilities, the rationality of environmental policy formulation, and the concrete measures of environmental protection. And the document was adopted in the form of text and diagrams to allow information users to obtain more information and deepen their understanding of the government's environmental responsibility behavior and make audit reports more credible. The Concise Guide to Environmental Protection and Sustainable Development is the latest announcement issued by the National Audit Office which using the latest data updated by the National Office of Official Statistics. It reflects the economic indicators and analysis result of the development of sustainability projects in the three aspects of society, economy and environment in England. The National Audit Office conducted further investigations into the contradictions between the conclusions reached by other institutions and auditors, and determined the final conclusion based on the 
investigation results. In the guide, the National Audit Office also listed the audit results of the institution on the specified areas and the evaluation results of the environmental audit committee to enhance the trust of information users in the guide.

\subsection{The Government Environmental Responsibility Audit Reports have a Promoting Effect}

The National Audit Office issued the Central Department Sustainability Report: An Update. This report shows that the relevant environmental departments have corrected the problems in the environmental governance process through the previous audit guidance, and practiced the principles of sustainable development, and continuously improved the intensity of environmental protection and resource control. It can be seen from this case that the audit report of the National Audit Office can promote relevant government departments to improve their environmental governance behavior and continuously improve the environmental responsibility performance mechanism, which truly meets the requirements of environmental protection and sustainable development.

\subsection{The Government Environmental Responsibility Audit Reports have Reference Value}

Environmental governance issues are complicated by regional differences and resource diversity. So environmental governance agencies need to constantly try and improve when implementing governance measures, and the National Audit Office needs to cooperate with multiple departments. Therefore, the National Audit Office visited relevant departments on site and conducted interviews and surveys to understand and analyze the current environmental situation. The publication of the survey results can provide references for other organizations and departments. The National Audit Office provided the Air Quality audit report, which clearly pointed out that the British government should fully understand the local government's funds and resource holdings to avoid the local government's financial difficulties. The local government should cooperate with other organizations. When government departments and organizations act together, it will help to improve the efficiency of environmental governance. At the same time, the report shows that the environmental governance action should be a continuous activity. Based on the lessons learned from the report, it can provide reference for other companies.

\section{THE REFERENCE OF GOVERNMENT ENVIRONMENTAL RESPONSIBILITY AUDIT IN CHINA}

\subsection{Develop Research-based Comprehensive Research Audit Reports on Government Environmental Responsibility}

The compiled research-based comprehensive audit reports on these major issues and released them publicly. After in-depth investigation and analysis of various government activities, these reports point out the problems of a certain project and give guidance. They consider the policy-making work of the policy-making department in combination with the national policy guidelines, predict the sustainable benefit of environmental governance projects, and provide more detailed and comprehensive research and audit reports .The government environmental responsibility research-type comprehensive audit report comprehensively considers the information and data released by multiple channels and agencies, and based on previous audit reports and successful governance experience. It objectively analyzes the necessity of environmental protection and the feasibility of policies in the context of environmental governance and the effectiveness of governance. It put forward appropriate suggestions for specific problems and use existing resources to scientifically and efficiently optimize the governance environment. At the same time, all departments will be united to exert synergy effects and work together to improve environmental issues. The research-based comprehensive audit report requires high information quality. And the information in report should be authoritative and professional.

\subsection{Actively Explore the Preparation of Natural Resource Balance Sheets}

All documents and materials related to the government environment may become the audit basis. Therefore, the data listed in the natural resources balance sheet will become one of the audit evidence, and these data and text are the content of the environmental responsibility audit. The design of the natural resource balance sheet will be an issue that the audit subject should pay attention to. It must not only truly and fully reflect the status and changes of the natural resources of the environmental responsibility related departments, but also be consistent with the audit standards. Actively exploring the preparation of natural resources balance sheets requires listening to multiple opinions, involving multiple audited departments and professional government agencies, quantifying environmental responsibilities and making the governance results of leading cadres more intuitive. 


\subsection{Establish an Environmental Target Accountability System}

The clear definition of the work responsibilities of the audited unit is an important basis for the government's environmental responsibility audit content. Under the premise of clarifying the environmental work responsibilities of the audited object, the workload of the audit team can be reduced, and the audit content and audit results will be more effective and comprehensive. Establishing an environmental target responsibility system is to evaluate and assess the performance of environmental responsibilities during the tenure of the audited object. The audit evaluation standard is to audit the content of the audit based on the environmental targets set before, and the responsibility is assigned to the leaders of each department to perform environmental responsibilities. Environmental responsibilities audit can distinguish between the parties that have achieved environmental goals and those that have not met the standards, which facilitates the later formulation of specific measures. The environmental target responsibility system should set up a reasonable audit work evaluation system, which combines qualitative and quantitative indicators to objectively reflect and evaluate the results of the audited unit's environmental governance work. Government departments related to the environment should clearly divide the responsibilities of their posts and assign environmental rights and responsibilities to individuals. In actual work, individuals and departments should strictly follow the list of powers and responsibilities to perform their respective tasks.

\subsection{Improve the Joint Meeting System of Government Environmental Responsibility Audit}

The improvement of the joint meeting system of government environmental responsibility audit will help the development of environmental responsibility audit work. Before the meeting, the participating members fully understood and investigated the problems of the audited units, the characteristics of environmental resources within the environmental jurisdiction, and the policy documents, laws and regulations in related fields. Sufficient preliminary investigations laid a good foundation for the work of the meeting. In addition, due to professional limitations, auditors should communicate with experts and technicians in related fields to reduce the limitations of auditors' professional competence. During the joint meeting, the participants of the joint meeting should discuss the deficiencies and improprieties of the current government departments in environmental governance, establish laws and regulations for parts not covered by laws in related fields, and put forward suggestions to relevant lawmaking departments to improve the environment liability legal system. In addition, the joint meeting should formulate a detailed plan for the development of environmental responsibility audits. Auditors can cooperate and communicate with professional big data talents, fully mine environmental resource data, and extract evidence related to audit objectives.

\section{CONCLUSION}

In recent years, the construction of ecological civilization has received increasing attention from the party and government, and it is an important part of the Chinese "economic, political, cultural, social, and ecological progress" development strategy. Environmental protection and the performance of environmental responsibilities complement each other, and the establishment of environmental protection responsibility system requires clear responsibilities, reasonable division of labor, and coordination and cooperation at all levels. As environmental issues are becoming more and more serious, China should conduct government environmental responsibility audits from top to bottom as soon as possible, so as to implement a nationwide mechanism of environmental responsibility for leading cadres.

\section{ACKNOWLEDGMENTS}

This research was financially supported by National Social Science Fund <The research of environmental responsibility internal audit based on the social responsibility report $>$.

\section{REFERENCES}

[1] Bovens, M.Two Concepts of Accountability: Accountability as a Virtue and as a Mechanism[J]. West European Politics,2017(33):946-967

[2] Karin Backstrand, Accountability of Networked Climate Governance: The Rise of Transnational Climate Partnerships[J], Global Environmental Politics, 2008, (3):27-36

[3] BJ Ermekbayeva, LA Bimendieva, NA Tovma., Environmental audit on the way of solving environmental problems in the oil and gas sector[J], International Journal of Innovative Technologies in Economy, 2016, (3):29-33

[4] Barton H, Bruder N. The Nature of Environment Auditing[J].A Guide to Local Environmental Auditing,2014,1(2):7-11

[5] Lightbody M.Environmental auditing: the audit theory gap[J].Accounting Forum, 2018, 24 (2) : 151-169 